\title{
Just-in-time information presentation: Improving learning a troubleshooting skill.
}

Citation for published version (APA):

Kester, L., Kirschner, P. A., \& van Merrienboer, J. J. G. (2006). Just-in-time information presentation: Improving learning a troubleshooting skill. Contemporary Educational Psychology, 31(2), 167-185.

https://doi.org/10.1016/j.cedpsych.2005.04.002

DOI:

10.1016/j.cedpsych.2005.04.002

Document status and date:

Published: 01/04/2006

Document Version:

Peer reviewed version

Please check the document version of this publication:

- A submitted manuscript is the version of the article upon submission and before peer-review. There can be important differences between the submitted version and the official published version of record. People interested in the research are advised to contact the author for the final version of the publication, or visit the DOI to the publisher's website.

- The final author version and the galley proof are versions of the publication after peer review.

- The final published version features the final layout of the paper including the volume, issue and page numbers.

Link to publication

\section{General rights}

Copyright and moral rights for the publications made accessible in the public portal are retained by the authors and/or other copyright owners and it is a condition of accessing publications that users recognise and abide by the legal requirements associated with these rights.

- Users may download and print one copy of any publication from the public portal for the purpose of private study or research.

- You may not further distribute the material or use it for any profit-making activity or commercial gain

- You may freely distribute the URL identifying the publication in the public portal.

If the publication is distributed under the terms of Article 25fa of the Dutch Copyright Act, indicated by the "Taverne" license above, please follow below link for the End User Agreement:

https://www.ou.nl/taverne-agreement

Take down policy

If you believe that this document breaches copyright please contact us at:

pure-support@ou.nl

providing details and we will investigate your claim.

Downloaded from https://research.ou.nl/ on date: 26 Apr. 2023 


\section{Running head: JUST-IN-TIME INFORMATION PRESENTATION}

This is a pre-print of the article that was published as:

Kester, L., Kirschner, P.A., \& Van Merriënboer, J.J.G. (2006). Just-in-time information presentation: Improving learning a troubleshooting skill. Contemporary Educational Psychology, $31,167-185$.

Copyright Elsevier, available online at http://www.elsevier.com/wps/find/journaldescription.cws_home/622811/description\#description

Just-in-time Information Presentation: Improving Learning a Troubleshooting Skill Liesbeth Kester $^{1}$, Paul A. Kirschner, and Jeroen J. G. van Merriënboer Educational Technology Expertise Center Open University of the Netherlands, Heerlen, the Netherlands

1 The authors gratefully acknowledge the assistance of Robert Bouwens, Stan Wilden, and their colleagues for their help in carrying out this experiment at Bernardinus College. Correspondence concerning this article should be addressed to Liesbeth Kester, Open University of the Netherlands, Educational Technology Expertise Center, P.O. Box 2960, 6401 DL Heerlen, The Netherlands. Telephone: +31 (0)45-5762428. Fax: +31 (0)455762802. Email: liesbeth.kester@ou.nl 
Just-in-time Information Presentation: Improving Learning a Troubleshooting Skill ${ }^{2}$

${ }^{2}$ The authors gratefully acknowledge the assistance of Robert Bouwens, Stan Wilden, and their colleagues for their help in carrying out this experiment at Bernardinus College. 


\begin{abstract}
Troubleshooting in a practice situation requires two types of information, namely for reasoning about the problem-cause and for finding an adequate solution (declarative information) and for manipulating the environment (procedural information). It is hypothesized that presenting this information piece-by-piece during practice (i.e., presentation of declarative and procedural information separately) frees up working memory and facilitates learning. Moreover, this effect is augmented when both information types are presented justin-time (i.e., declarative information before practice and procedural information during practice). This should yield highest test performance and instructional efficiency, which is defined as higher test performance combined with lower mental effort during practice. Eighty-five students (49 male, 36 female; $M=15.2$ years, $S D=.59$ ) participated in a $2 \times 2$ factorial experiment with the factors timing of declarative information and timing of procedural information, both before or during practice. Transfer test scores and transfer efficiency scores support the first hypothesis; the second hypothesis was not supported.
\end{abstract}


Just-in-time Information Presentation: Improving Learning a Troubleshooting Skill

Modern curricula make use of powerful e-learning environments for the acquisition of cognitive skills. Such environments contain practice problems (e.g., simulations) and related information (e.g., text and animation; see Merrill, 2002; Reigeluth, 1999; Van Merriënboer \& Kirschner, 2001). During problem solving in such environments learners (1) master cognitive skills that require integration of the knowledge, skills, and attitudes necessary for effective performance, (2) learn to coordinate cognitive skills, and, eventually, (3) become able to transfer what is learned to their daily life or future work settings. Acquiring cognitive skills while working in complex learning environments, however, tends to cognitively tax the learner to such an extent that skill acquisition may be hampered or frustrated. Implementing guidelines from cognitive load theory (Sweller, 1988) could prove beneficial to facilitating the acquisition of cognitive skills in such environments.

Cognitive load theory distinguishes three types of cognitive load, namely intrinsic, extraneous, and germane load. These three types of load need to be optimally balanced in order to make good use of limited working memory capacity (Baddeley, 1992; Miller, 1956). According to Sweller, van Merriënboer, and Paas (1998), intrinsic cognitive load is inherent to a learning task and is determined by the degree of element interactivity in that task. Extraneous cognitive load is caused by those processes a learner engages in while interacting with the instructional material that are not beneficial for learning. Examples of activities that induce extraneous cognitive load are mentally integrating different sources of information (e.g., separate information in a figure and a text) or searching for relevant information in order to understand the subject matter. Finally, germane cognitive load is load associated with processes that are beneficial for learning. Variability of learning tasks, for example, may stimulate learners to construct better cognitive schemata (Spiro, Coulson, Feltovich, \& Anderson, 1988; Sweller et al., 1998) and can be considered, thus, to being germane to 
learning. In general, a well designed learning environment should properly manage intrinsic load, minimize extraneous load, and optimize germane load within the boundaries of working memory capacity. The focus of this study is on managing intrinsic load and minimizing extraneous load in relation to the information needed to solve practice tasks and acquire troubleshooting skills.

In this study, two types of information are distinguished, namely declarative and procedural. Declarative information refers to the conceptual model of how a domain is organized (see the textual information in the right half of Figure 1 for an example) and enables learners to construct cognitive schemata through elaboration (Reigeluth, 1983, 1999). The declarative information presented is gradually coupled to already existing, relevant cognitive schemata in long term memory of the learner. Elaboration of declarative information yields cognitive schemata that contain domain-general knowledge which is particularly useful when learners have to deal with unfamiliar problem situations. Such situations require interpretation of cognitive schemata, that is, different use of the same domain-general knowledge. In the study presented here, reasoning about the differences between various connections in electrical circuits (e.g., series or parallel) and their influence on the circuit and the properties of elements in the circuit is just such a situation.

Procedural information refers to task-specific rules along with their related facts, principles, or concepts which are necessary for schema automation (see the textual information in the left half of Figure 1 for an example). This information enables learners to form productions through knowledge compilation (Anderson, 1996): The translation of procedural information into procedural knowledge (i.e., internalized rules). Knowledge compilation of procedural information yields productions containing domain-specific knowledge particularly useful for dealing with familiar problem situations because such situations require the same use of the same domain-specific knowledge. In the study presented 
here, this allows the learner to recognize a switch and the need to throw it to close a circuit or to recognize a short circuit and be able to fix it.

Intrinsic load can, first, be managed by presenting both the declarative and the procedural information piece-by-piece. Instead of allocating working memory capacity to processing both declarative and procedural information at the same time, learners can allocate the same amount of working memory capacity to the declarative and the procedural information, one piece at a time. In addition, intrinsic load can be managed by presenting the declarative information just-in-time, that is, before learners start solving the practice tasks. Since this declarative information typically has a higher degree of element interactivity (i.e., more interconnected elements) than the procedural information, presenting it during practice might require too much working memory capacity. When declarative information is presented before practice, all working memory capacity can be allocated to elaborating it and, thus, to schema acquisition.

To minimize extraneous load, procedural information should also be presented just-intime, but here that means during practice-task solution. Extensive research has been carried out on the split attention effect (for an overview, see Sweller et al., 1998; for a study in this domain, see Kester, Kirschner, \& van Merriënboer, in press). This research indicates that extraneous load is significantly reduced when mutually referring information resources are integrated, rather than when they are separated in time or space. Eliminating split attention in instructional material enables learners to allocate all available working memory capacity to processes relevant for learning. By presenting the procedural information fully integrated within the practice tasks, temporal and spatial split attention is avoided and all relevant information is active in working memory when it is applied to problem solving, a necessary precondition for knowledge compilation to occur (Kester, Kirschner, van Merriënboer, \& Bäumer, 2001). 
To investigate the effectiveness and efficiency of piece-by-piece and just-in-time information presentation, four information-presentation formats are compared, namely:

1. presenting declarative information before practice and procedural information during practice (i.e., piece-by-piece and just-in-time),

2. presenting declarative information during practice and procedural information before practice (i.e., piece-by-piece),

3. presenting both declarative and procedural information before practice, and

4. presenting both declarative and procedural information during practice.

Effectiveness is measured by performance on two types of test tasks. Equivalent test tasks are tasks that are analogous to the practice tasks and, therefore, have a high level of familiarity to the learner. These tasks make use of the same circuit elements which were used during learning. Transfer test tasks are tasks that use some of the same elements used during learning along with new elements and have, thus, a lower level of familiarity. In such a transfer task, a motor would be used instead of a lamp to draw current in a circuit. Although learners need both specific schemata and general schemata to solve both types of test-tasks, solving equivalent tasks relies more on using specific schemata acquired through compilation of procedural information while solving transfer tasks increasingly relies on general schemata acquired through elaboration of the declarative information as the familiarity of these tasks decreases.

While test performance indicates the effectiveness of the information presentation formats, the costs at which this performance is obtained indicates their efficiency. Instructional efficiency looks at the learning outcomes (i.e., test performance) in relation to the working memory capacity allocated during practice (Tuovinen \& Paas, 2004; Paas, Tuovinen, Tabbers, \& van Gerven, 2003; Paas \& van Merriënboer, 1993). Instructional efficiency indicates the extent to which learners, during practice, were able to allocate their 
working memory capacity to processes relevant for learning. High test performance in combination with low allocation of working memory capacity is highly efficient and indicates that the allocated working memory capacity was used for processes relevant to learning (i.e., low extraneous load). Low test performance in combination with high allocation of working memory capacity during practice is less efficient and indicates that a substantial amount of working memory capacity was allocated to processes not relevant to learning (i.e., high extraneous load).

Performance efficiency provides information on the efficiency of the test performance, by looking at test performance in relation to the working memory capacity used to reach this performance. Performance efficiency indicates the extent to which learners were able to acquire adequate schemata during practice. High test performance in combination with low allocation of working memory capacity during the test is highly efficient and indicates that learners were able to form adequate schemata during practice to help them solve the test problems. Low test performance in combination with high allocation of working memory capacity during the test is less efficient and indicates that learners were not able to form adequate schemata during practice and possibly had to resort to more cognitively demanding, weak-method problem-solving strategies.

The main hypothesis in this study is that the format where the declarative information is presented before practice and procedural during practice along with the format where the declarative information is presented during practice and procedural information before (i.e., piece-by-piece) yield a higher test performance, instructional efficiency, and performance efficiency than those formats that present both information types simultaneously, either before or during practice, because the piece-by-piece formats better manage intrinsic load. Moreover, it is hypothesized that the information presentation format that presents declarative information before practice and procedural information during practice (i.e., piece-by-piece 
and just-in-time) will yield higher test performance, instructional efficiency, and performance efficiency than the other three formats because in this format the intrinsic load is properly managed and the extraneous load is minimized.

\section{Method}

\section{Participants}

Eighty-five tenth-grade students at Bernardinus College, an academic high school in Heerlen, The Netherlands (49 male, 36 female; $M=15.2$ years, $S D=.59$ ), participated in this study. All participants spoke Dutch as their first language, the language in which the instruction was given. They voluntarily participated in a physics lesson on electrical circuits, using a computer-based learning environment. No specific grade was given for this lesson. All participants followed the same physics education curriculum, which started in ninth grade. They were all equally familiar with the topic of the lesson because they all studied relevant theory in the previous academic year. As compensation for their participation they received a music compact disc of their own choice.

\section{Materials}

Physics lesson. Crocodile Physics $1.5^{\circledR}$, a simulation program for secondary school science classes, was used to develop the physics lesson for this experiment. The computerbased lesson contained an introduction, declarative information, procedural information, ten practice-troubleshooting tasks, and ten test-troubleshooting tasks. During practice, the participants had to use the declarative and procedural information given to troubleshoot a malfunctioning electrical circuit. They had to give a description of the problem, diagnose the cause of the problem, and present a solution to the problem. The aim of the lesson was to teach the participants to solve problems related to current (e.g., too high or too low), wrongly connected elements (e.g., lamps, switches, and meters in series or parallel), and short circuits. This was tested in ten test tasks where participants had to apply what they had learned during 
practice to ten novel malfunctioning circuits. No declarative or procedural information was available during the test.

Information presentation. The troubleshooting practice tasks, consisting of malfunctioning electrical circuits, were accompanied by declarative and procedural information presented either before practice, during practice, or before and during practice. The declarative information was divided over three screens while the procedural information fit on one screen. All conditions contained the exact same amount of information, both declarative and procedural. Four information presentation formats were distinguished in a $2 \mathrm{x}$ 2 factorial design with the factors being: 'timing of declarative information presentation', before or during practice, and 'timing of procedural information presentation', also before or during practice. In the 'declarative before, procedural during' format the declarative information was presented before practice while the procedural information was presented during practice. In the 'declarative during, procedural before' format the declarative information was presented during practice while the procedural information was presented before practice. In the 'declarative before, procedural before' format both declarative information and procedural information were presented before practice. Finally, in the 'declarative during, procedural during' format both declarative and procedural information were presented during practice. For an example of a practice task see Figure 1.

\section{***INSERT FIGURE 1 ABOUT HERE***}

Practice tasks. Participants received ten practice tasks. The circuits in the practice tasks made use of six elements, namely: a toggle switch, a lamp, a battery, a resistor, a voltmeter, and an ammeter. During practice, all circuits contained all six elements. Every practice task consisted of three parts. The participants could obtain a maximum of 30 points by giving a correct problem description (1 point), a correct problem cause (1 point), and a correct problem solution (1 point) for the malfunctioning circuits. For example, the inserted 
battery in one practice task is too strong for the elements in the circuit. In this task the following correct responses could be made: (1) problem description: the lamp explodes (=1 point), (2) problem cause: the power supply, for instance the battery, is too strong for the lamp (= 1 point), and (3) problem solution: insert a weaker battery (=1 point). The problem causes that were implemented in the practice tasks were related to current (i.e., too high or too low), wrongly connected elements or a short circuit. Every task contained only one problem.

To determine interrater reliability, practice performance scores of eight participants were determined by two raters. The interrater reliability for practice performance of the two raters was .87 (Intraclass Correlation Coefficient, SPSS). The internal consistency of the practice items was .82 (Cronbach's alpha).

Test tasks. After the ten practice tasks, participants received ten test tasks. The test tasks also consisted of malfunctioning electrical circuits with problems related to current, wrongly connected elements and short circuits that were designed in Crocodile Physics ${ }^{\circledR}$, but without the accompanying information. Five of the ten test tasks were equivalent to the practice tasks, that is, they contained the same elements as the practice tasks. The other five tasks also contained one or two new elements, namely: a variable resistor, a fuse, an LED, a buzzer and push-button switch, or a motor and gears.

The equivalent test-tasks were meant to determine whether the participants had formed specific schemata to help them solve the familiar aspects of the test task. The test tasks that contained a new element, the transfer test-tasks, were meant to determine whether the participants were able to construct specific schemata plus those general schemata that help them solve the unfamiliar aspects of the test task. The participants could obtain a maximum of 15 points for the five equivalent tasks and 15 points for the five transfer tasks. As was the case in practice, they received one point for each correct description, cause or solution. To determine the interrater reliability the total test performance scores of eight participants were 
determined by two raters. The interrater reliability for the test performance on the equivalent tasks of the two raters was .87 (Intraclass Correlation Coefficient, SPSS) and for the transfer tasks it was .92. The internal consistencies of the equivalent tasks and the transfer tasks were .64 and .63 (Cronbach's alpha), respectively.

Mental effort measurement. Mental effort was used as an index of cognitive load. It refers to the amount of working memory capacity allocated to problem solving. Mental effort was measured during both practice and the test with a 9-point rating-scale (Paas, 1992; Paas, van Merriënboer, \& Adam, 1994). The mental effort measures ranged from very, very low mental effort (1) to very, very high mental effort (9). The rating-scale was administered electronically during both practice and the test directly after each troubleshooting task. After each task, participants were asked: "How much mental effort did it require to find a solution for the problem(s) in the preceding circuit?" Moreover, after the ten practice tasks a separate mental effort measurement was administered for the subject matter. The participants were asked: "How much mental effort did it require to understand all subject matter?" The internal consistency of the mental effort measures was .83 (Cronbach's alpha) for the ten practice tasks, .69 for the five equivalent test tasks, and .68 for the five transfer test tasks.

\section{Learning and performance efficiency}

The Paas and van Merriënboer procedure (1993; see also Paas et al., 2003) was used to calculate efficiency. First, the performance measures and the mental effort measures for each participant are transformed into $z$-scores, using the grand mean across conditions. Then, the mean $z$-scores for every condition is represented in a Cartesian coordinate system with Mental effort $z$-scores on the horizontal axis and Performance $z$-scores on the vertical axis (see Figure 2). The line $P=M$ through the origin indicates a neutral efficiency (slope $=45^{\circ}$ ). The efficiency, $E$, is calculated as the perpendicular distance from a data point in the coordinate 
system to the line $P=M$ (Paas \& van Merriënboer, 1993). The formula for calculating this distance is:

$$
P_{\text {erformance }}-M_{\text {ental Effort }}
$$

$E \quad=$

$$
\sqrt{ } 2
$$

Equal performance $(P)$ and mental effort $(M)$ z-scores yield an instructional efficiency of zero, a neutral score. When $P>M$, the instructional material is more efficient, indicated by a positive value because the performance is higher than might be expected on the basis of perceived mental effort (i.e., the data point is to the left of the diagonal). When $P<M$, the material is less efficient, indicated by a negative value because the performance is lower than might be expected on the basis of perceived mental effort (i.e., the data point is to the right of the diagonal). Instructional efficiency is calculated on the basis of perceived mental effort during practice and test performance. The performance efficiency is calculated on the basis of perceived mental effort during the test and test performance.

\section{***INSERT FIGURE 2 ABOUT HERE***}

\section{Procedure}

Participants were randomly assigned to one of the four formats. The computers in a computer room were configured beforehand with one of the four formats so that all formats were divided, per row, over the available computers. The monitors were shut off and the participants blindly choose a computer to work on when they walked in.

Once all participants had chosen a computer and were seated, they received an oral instruction which stressed that they had to work independently, observe the time limit, work seriously, carefully study the information that precedes the practice tasks, and not ask questions during the experiment. It was emphasized that they were not allowed to skip any 
part of the answer (problem description, cause or solution) even if they did not know the answer. In the latter case they were advised to give the response 'no answer' or 'do not know'. It was made clear that all of the responses would be checked after the session to determine whether there were omissions regarding the answers on the troubleshooting tasks and the mental effort measures. They were told that the aim of the experiment was to determine if it is useful to integrate this kind of simulation-software into regular education and, if this is the case, how this should be done. It was made clear that the physics lesson contained ten practice tasks and ten test tasks and that it was their job to give a description, cause, and solution for the problem in the malfunctioning circuit. Before the participants actually started with the physics lesson they were 'walked through' an example of the type of troubleshooting task they were about to receive in class, with respect to the functional aspects of the learning environment only (i.e., how Crocodile ${ }^{\circledR}$ worked). During this example they could only ask questions about the learning environment and the procedure. This example was not accompanied by declarative or procedural information. All efforts were made to ensure that the whole procedure was clear to all participants before the actual experiment started.

All participants had 100 minutes available to work through the introduction and to complete the lesson. In the introduction, participants received information on (1) what to expect such as the number of tasks, available time, and how to switch a circuit on and off; (2) how to navigate within the lesson such as left and right arrows to go back or forth in the lesson, and how to jump to a practice task or a test task by clicking on different icons, and (3) the rules during the experiment such as that taking notes or changing the computer's configuration was not allowed and the work had to be done individually. After the introduction, the participants could go through the practice phase and the test at their own pace, but in a fixed order. Once the participants started working on the practice tasks, they were not allowed to return to information presented before practice and they could not go 
back to the practice tasks once they started working on the test tasks. Participants could, however, move back and forth freely within each segment, that is, in the 'before' information part, the practice part, and the test part.

Results

\section{Practice tasks}

See Table 1 for an overview of the results for the practice tasks.

\section{***INSERT TABLE 1 ABOUT HERE***}

Practice performance. An alpha level of .05 was used for all statistical tests. ANOVA revealed a main effect for timing of declarative information presentation on practice performance, $F(1,85)=4.26 ; M S E=95.04 ; p<.05 ; \eta^{2}=0.05$. Participants receiving declarative information during practice $(M=17.64 ; S D=4.65)$ performed better than those receiving declarative information before practice $(M=15.52 ; S D=4.72)$. There was no effect of timing of procedural information and no interaction effect on practice performance. Tukey's HSD test showed no significant differences between information presentation formats.

Mental effort. Perceived mental effort during practice and for understanding the subject matter were considered separately. ANOVA yielded an interaction between the timing of declarative and procedural information on mental effort during practice, $F(1,85)=4.26$; $M S E=6.36 ; p<.05 ; \eta^{2}=0.05$ (see Figure 3). If declarative information was presented before practice, participants reported expending less mental effort to solve the tasks when procedural information was presented during practice $(M=4.4 ; S D=1.16)$ than when procedural information was also presented before practice $(M=4.9 ; S D=1.33)$. If declarative information was presented during practice, the participants reported expending less mental effort to solve the tasks when procedural information was presented before practice $(M=4.1$; $S D=1.46)$ than when procedural information was also presented during practice $(M=4.8$; 
$S D=.9)$. Tukey's HSD test showed no significant differences between information presentation formats. No differences of the information presentation formats were found on the mental effort reported for understanding the subject matter.

\section{***INSERT FIGURE 3 ABOUT HERE***}

Test tasks

See Table 2 for an overview of the results for the test tasks.

\section{***INSERT TABLE 2 ABOUT HERE***}

Test performance. For performance on the transfer test tasks, ANOVA revealed an interaction between timing of declarative and timing of procedural information in the expected direction, $F(1,85)=4.68 ; M S E=30.5 ; p<.05 ; \eta^{2}=0.06$ (see Figure 4). If declarative information was presented before practice, the presentation of procedural information during practice led to higher performance on the transfer test-tasks $(M=6.90$; $S D=2.00)$ than when procedural information was also presented before practice $(M=5.57$; $S D=2.68)$. Conversely, when declarative information was presented during practice, the presentation of procedural information before practice led to higher performance on the transfer test-tasks $(M=6.31 ; S D=2.83)$ than when procedural information was also presented during practice $(M=5.24 ; S D=2.59)$.

This interaction effect indicates that piece-by-piece presentation of declarative and procedural information leads to better performance on the transfer test-tasks than simultaneous presentation of both information types. This was confirmed with an additional contrast analysis. Meaningful differences were found between the 'declarative before, procedural during' format and the 'declarative during, procedural before' format in which the information was presented piece-by-piece and the 'declarative before, procedural before' format and the 'declarative during, procedural during' format in which the information was presented simultaneously, $F(1,85)=4.68 ; M S E=30.50 ; p<.05 ; \eta^{2}=0.06$. Moreover, a 
second contrast analysis was carried out to see whether the 'declarative before, procedural during' format led to better performance on the transfer test tasks than the other three formats. This analysis yielded no significant differences, $F(1,85)=4.68 ; M S E=24.01 ; p=0.058$; $\eta^{2}=0.04$

No significant differences for the information presentation formats were found on performance of the equivalent test-tasks.

\section{***INSERT FIGURE 4 ABOUT HERE***}

Mental effort. No significant differences of the information presentation formats were found on reported mental effort for either the transfer test-tasks or the equivalent test-tasks.

\section{Instructional and performance efficiency.}

For the transfer test, ANOVA revealed an interaction that partially showed the expected pattern for instructional efficiency between timing of declarative information and timing of procedural information, $F(1,85)=7.92 ; M S E=8.7 ; p<.01 ; \eta^{2}=0.09$. If declarative information was presented before practice, it was more efficient to present procedural information during practice $(M=.32 ; S D=.83)$ than to present it before practice $(M=-.29 ; S D=1.13)$. If declarative information was presented during practice, it was more efficient to present procedural information before practice $(M=.34 ; S D=1.2)$ than to present it during practice $(M=-.33 ; S D=.98$; see Figure 5a).

This interaction effect indicates that piece-by-piece presentation of declarative and procedural information leads to higher instructional efficiency than simultaneous presentation. This was confirmed with an additional contrast analysis. Meaningful differences were found between the 'declarative before, procedural during' format and the 'declarative during, procedural before' format in which the information was presented piece-by-piece and the 'declarative before, procedural before' format and the 'declarative during, procedural during' format in which the information was presented simultaneously, $F(1,85)=7.92 ; M S E=8.7$; 
$p<.01 ; \eta^{2}=0.09$. A second contrast analysis carried out to determine whether 'declarative before, procedural during' led to a higher instructional efficiency than the other three formats yielded no significant results.

For the performance efficiency of the transfer test, ANOVA also revealed an interaction between timing of declarative information and timing of procedural information, showing the same pattern as for instructional efficiency, $F(1,85)=4.20 ; M S E=4.53 ; p<.05$; $\eta^{2}=0.05$. If declarative information was presented before practice, it was more efficient to present procedural information during practice $(M=.21 ; S D=.87)$ than to also present it before practice $(M=-.28 ; S D=1.05)$. If declarative information was presented during practice, it was more efficient to present procedural information before practice $(M=.26$; $S D=1.22)$ than to also present it during practice $(M=-.17 ; S D=.98$; see Figure $5 \mathrm{~b})$. No effects of the information presentation formats were found on either the instructional efficiency or on the performance efficiency for the equivalent test-tasks.

This interaction effect indicates that piece-by-piece presentation of declarative and procedural information leads to a higher performance efficiency than simultaneous presentation of these information types. This was confirmed with an additional contrast analysis. Meaningful differences were found between the 'declarative before, procedural during' format and the 'declarative during, procedural before' format in which the information was presented piece-by-piece and the 'declarative before, procedural before' format and the 'declarative during, procedural during' format in which the information was presented simultaneously, $F(1,85)=4.20 ; M S E=4.53 ; p<.05 ; \eta^{2}=0.05$. A second contrast analysis carried out to determine whether the 'declarative before, procedural during' led to a higher performance efficiency than the other three formats yielded no significant results. 


\section{Discussion}

Support is found for the first hypothesis. It is clearly better to present the declarative information and the procedural information piece-by-piece instead of simultaneously. Learners in the 'declarative before, procedural during' and the 'declarative during, procedural before' information presentation formats (piece-by-piece) obtained higher transfer-test scores than learners in the 'declarative before, procedural before' and 'declarative during, procedural during' formats (simultaneous). Furthermore, learners in the piece-by-piece formats reported lower mental effort ratings during practice than learners in the simultaneous formats. The combination of low investment of mental effort during practice and high performance on the transfer test tasks is reflected in a high instructional efficiency. Thus, as hypothesized, learners in the formats that presented the necessary information piece-by-piece had higher instructional efficiency scores than learners in the formats where both information types were presented simultaneously whether before or during practice. Presumably, learners in the piece-by-piece formats were better able to allocate their working memory capacity to processes relevant for learning. Moreover, the performance efficiency scores indicate that these learners not only show a higher performance on the transfer test tasks, but also reach this performance with a proportionally lower investment of mental effort in test problem solving. It appears that learners in the piece-by-piece formats were better able to form adequate schemata which helped them solve the transfer test tasks. With regard to the second hypothesis, just-in-time information presentation did not result in higher instructional efficiency or performance efficiency compared to the other three formats.

These results raise two questions. First, why did the transfer test scores of learners in the 'declarative before, procedural during' format not significantly differ, as predicted, from the transfer-test scores of learners in the 'declarative during, procedural before' format? The same is true for the mental effort, instructional efficiency, and performance efficiency scores. 
A possible explanation for this is that a system-controlled approach was taken to test the hypotheses regarding just-in-time information presentation. This means that learners received the necessary information just when it was needed to meet the task requirements based on theoretical assumptions made by the experimenters. The learners themselves had little or no control over information presentation; it simply was presented on the computer screen. Although the information presented might have been just-in-time from a theoretical point of view, the learners might not have perceived it as being presented just-in-time (for them). This might have interfered with the learning processes involved in cognitive skill acquisition.

In addition, the learners might not perceive the declarative and procedural information as being really different. The declarative information contained mostly linear prose in which some analogies and examples were added. It is possible that the linearity of the declarative information made it possible for the learners to serially process this information which is associated with low element interactivity and thus low intrinsic load. In this way the declarative information resembles the procedural information which contained successive sentences which could also be processed serially. In other words, the declarative information may have had a lower intrinsic load than expected. The unexpected success of the 'declarative during, procedural before' format could be explained based on this alternative explanation. When the declarative and procedural information both have a low intrinsic load, both formats could be rephrased as a 'low intrinsic load information before, low intrinsic load information during' format. The only difference is that the procedural information is temporally and spatially integrated in the electrical circuits used during practice while the declarative information is only temporally integrated. This, however, might have been sufficient since the procedural information directly refers to the electrical circuit which makes spatial integration necessary while the declarative information only indirectly refers to the electrical circuit which makes temporal integration sufficient. 
The second question is: Why is there no difference between formats for the equivalent test tasks? In this respect the (un)familiarity of the transfer test tasks to the practice tasks has to be discussed. On the continuum from near transfer to far transfer, the transfer tasks used in this study were more at the near transfer end of this continuum than the far transfer end. Although, in general, the participants scored higher on the equivalent test-tasks than on the transfer test-tasks (see Table 2) - which seems to indicate that the transfer test-tasks were more difficult for them - the transfer tasks were still very similar to the equivalent test-tasks and the practice tasks. This has consequences for the underlying assumptions. It was assumed that the more unfamiliar the test task was, the more learners had to rely on their general schemata of the problem domain acquired through elaboration of the declarative information. Since the transfer test tasks were rather similar to the practice tasks, the specific schemata might have been sufficient to solve these tasks. However, the transfer test performance and performance efficiency were higher for the learners in the piece-by-piece formats who were apparently better able to form more adequate specific schemata than the learners in the simultaneous formats.

Participants in all formats applied what they had learned equally well on familiar test tasks, while participants in the piece-by-piece formats were better able to solve the transfer test tasks. In other words, participants in all formats were equally able to compile specific schemata, but the participants in the piece-by-piece formats were able to construct more adequate specific schemata. Since the practice tasks were solution oriented (i.e., participants had to give a problem description, a cause, and a solution for the problem) all participants were forced to apply the procedural information during practice to come up with an answer. The assignment itself, thus, directed the attention of the participants to the procedural information. Additionally, since the practice tasks did not cause cognitive overload (i.e., the invested mental effort during practice never exceeded the rating 'not low, not high'), 
knowledge compilation and the forming of specific schemata was possible in all formats. This solution-orientedness of the participants might mean that they did not pay attention to the declarative information unless their attention was specifically directed to it by presenting this information separately from the procedural information. This would explain why participants in the piece-by-piece formats performed equally well on the equivalent test tasks and better on the transfer test than participants in the other - simultaneous - formats. Participants in these formats were more inclined to not only include the procedural information, but also the declarative information in schema acquisition which could explain why their specific schemata were more effective and efficient than the specific schemata of participants in the other formats.

Future research should help strengthen the theoretical explanations for the results of this study. First, experiments should be carried out to explore the effects of learner-control over information presentation. Although self-regulated learning sometimes leads to superior learning outcomes (Zimmerman, 2002), studies show that only a few learners exhibit selfregulated behaviors of their own accord (Hofer, Yu, \& Pintrich, 1998). It seems, therefore, wise to not only give learners control over the information presentation, but also to support them in properly using this information. Second, eye-movement measurements could be used to gain more insight into the learner's attentional processes during information processing. In this way, just-in-time information presentation can be refined or optimized by (re)directing learners' attention during problem solving. Special attention should be given to formulating the assignment accompanying the practice tasks because this might be very powerful in directing attention to particular types of information. Third, to test the nature of the schemata (i.e., specific or general) formed during practice, more direct measures of these schemata are needed such as in-depth analysis of verbal protocols to yield more insight into learners' reasoning and underlying cognitive schemata. Finally, it is necessary to replicate the results of 
this study using more complex declarative information, other types of tasks (e.g., design problems or categorization problems), and tasks in other learning domains.

The practical implications of this study are straightforward. Relevant information should be distributed in a way that helps manage cognitive load. The presentation of all information relevant to solving problems both before learners start to work on the tasks and during the problem solving process is sub-optimal. It is better to present part of the information before problem solving and part of it during problem solving.

To conclude, this study reveals a positive difference in effectiveness and efficiency for information presentation formats presenting declarative and procedural information piece-bypiece before or during practice above information presentation formats presenting both information types simultaneously before or during practice. The hypothesis that piece-bypiece presentation of declarative and procedural information has beneficial effects on learning outcomes was confirmed. These findings are particularly important for the design of problem solving instruction because more and more educational approaches stress the importance of meaningful problem solving with realistic learning tasks. This study showed that the distribution of information presentation in relation to problem solving strongly affects the success of these instructional methods. 


\section{References}

Anderson, J. R. (1996). ACT: A simple theory of complex cognition. American Psychologist, $51,355-365$.

Baddeley, A. D. (1992). Working memory. Science, 255, 556-559.

Hofer, B. K., Yu, S. L., \& Pintrich, P. R. (1998). Teaching college students to be selfregulated learners. In D. H. Schunk, \& B. J. Zimmerman (Eds.) Self-regulated learning: From teaching to self-reflective practice (pp. 57-85). New York, NY, US: Guilford Publications.

Kester, L. Kirschner, P. A., \& van Merriënboer, J. J. G. (in press). The management of cognitive load during complex cognitive skill acquisition by means of computer simulated problem solving. British Journal of Educational Psychology.

Kester, L., Kirschner, P. A., van Merriënboer, J. J. G., \& Bäumer, A. (2001). Just-in-time information presentation and the acquisition of complex cognitive skills. Computers in Human Behavior, 17, 373-391.

Merrill, M. D. (2002). First principles of instruction. Educational Technology, Research and Development, 50(3), 43-59.

Miller, G. A. (1956). The magical number seven plus or minus two: Some limits on our capacity for processing information. Psychological Review, 63, 81-97.

Paas, F. (1992). Training strategies for attaining transfer of problem-solving skill in statistics: A cognitive-load approach. Journal of Educational Psychology, 84, 429-434.

Paas, F., Tuovinen, J. E., Tabbers, H. K., \& van Gerven, P. W. M. (2003). Cognitive load measurement as a means to advance cognitive load theory. Educational Psychologist, 38(1), 63-71. 
Paas, F., \& van Merriënboer, J. J. G. (1993). The efficiency of instructional conditions: An approach to combine mental effort and performance measures. Human Factors, 35, 737-743.

Paas, F., van Merriënboer, J. J. G., \& Adam, J. J. (1994). Measurement of cognitive load in instructional research. Perceptual and Motor Skills, 79, 419-430.

Reigeluth, C. M. (Ed.). (1983). Instructional design theories and models: An overview of their current status. Hillsdale, NJ: Lawrence Erlbaum.

Reigeluth, C. M. (Ed.). (1999). Instructional design theories and models: A new paradigm of instructional theory. Mahwah, NJ: Lawrence Erlbaum.

Spiro, R. J., Coulson, R. L., Feltovich, P. J., \& Anderson, D. K. (1988). Cognitive flexibility theory: Advanced knowledge acquisition in ill-structured domains. In V. Patel (Ed.), Proceedings of the $10^{\text {th }}$ Annual Conference of the Cognitive Science Society. Hillsdale, NJ: Lawrence Erlbaum.

Sweller, J. (1988). Cognitive load during problem solving: Effects on learning. Cognitive Science, 12, 257-285.

Sweller, J., van Merriënboer, J. J. G., \& Paas, F. (1998). Cognitive architecture and instructional design. Educational Psychology Review, 10, 251-296.

Tuovinen, J. G., \& Paas, F. (2004). Exploring multidimensional approaches to the efficiency of instructional conditions. Instructional Science, 32, 135-152.

Van Merriënboer, J. J. G., \& Kirschner, P. A. (2001). Three worlds of instructional design: State of the art and future directions. Instructional Science, 29, 429-441.

Zimmerman, B. J. (2002). Achieving academic excellence: A self-regulatory perspective. In M. Ferrari (Ed.) Pursuit of excellence through education (pp. 85-110). Mahwah, NJ: Lawrence Erlbaum. 
Table 1

Overview of Results for the Practice Task.

\begin{tabular}{|c|c|c|c|c|c|c|c|c|}
\hline & \multicolumn{8}{|c|}{ Information presentation format } \\
\hline & \multicolumn{4}{|c|}{ Piece-by-piece } & \multicolumn{4}{|c|}{ Simultaneous } \\
\hline & $M$ & $S D$ & $M$ & $S D$ & $M$ & $S D$ & $M$ & $S D$ \\
\hline Mental effort during practice* (1-9) & 4.44 & 1.16 & 4.13 & 1.46 & 4.88 & 1.33 & 4.80 & .89 \\
\hline Mental effort for subject matter (1-9) & 4.29 & 1.49 & 4.08 & 2.25 & 3.93 & 1.91 & 5.56 & 2.06 \\
\hline
\end{tabular}

$* p<.05$ for timing of declarative information on practice performance, and for the interaction of declarative information $\mathrm{x}$ procedural

information on mental effort during practice.

${ }^{\mathrm{a}} \mathrm{Dec}=$ Declarative information; Proc $=$ Procedural information; $\mathrm{B}=$ Before, and $\mathrm{D}=$ During. 
Table 2

Overview of Results for the Test Tasks

\begin{tabular}{|c|c|c|c|c|c|c|c|c|}
\hline & \multicolumn{8}{|c|}{ Information presentation format } \\
\hline & \multicolumn{4}{|c|}{ Piece-by-piece } & \multicolumn{4}{|c|}{ Simultaneous } \\
\hline & $M$ & $S D$ & $M$ & $S D$ & $M$ & $S D$ & $M$ & $S D$ \\
\hline Performance on the transfer test tasks* & 6.90 & 2.00 & 6.31 & 2.83 & 5.57 & 2.68 & 5.24 & 2.59 \\
\hline \multicolumn{9}{|l|}{$(\operatorname{Max} .=15)$} \\
\hline Performance efficiency* & .21 & .87 & .26 & 1.22 & -.28 & 1.05 & -.17 & .98 \\
\hline & \multicolumn{8}{|c|}{ Equivalent test tasks } \\
\hline Performance on the equivalent test tasks & 7.00 & 2.60 & 6.98 & 2.66 & 7.64 & 2.83 & 7.78 & 2.35 \\
\hline \multicolumn{9}{|l|}{$(\mathrm{Max} .=15)$} \\
\hline Mental effort (1-9) & 4.71 & 1.27 & 4.81 & 2.01 & 5.08 & 1.52 & 4.88 & 1.27 \\
\hline
\end{tabular}

$* \quad p<.05$ for the interaction of declarative information x procedural information on performance and performance efficiency of the transfer test.

** $p<.01$ for the interaction of declarative information x procedural information on instructional efficiency of the transfer test.

a $\quad$ Dec $=$ Declarative information; Proc $=$ Procedural information; $\mathrm{B}=$ Before, and $\mathrm{D}=$ During. 
Figure Captions

Figure 1. An example of a practice task in the 'declarative during, procedural during' format. The declarative information is presented in the right-hand frame and the procedural information is integrated in the circuit diagram.

Figure 2. Efficiency measures in a Cartesian coordinate system.

Figure 3. The interaction between the timing of declarative information (i.e., before or during practice) and the timing of procedural information (i.e., before or during practice) for mental effort during practice.

Figure 4. The interaction between the timing of declarative information (i.e., before or during practice) and the timing of procedural information (i.e., before or during practice) for the transfer test task performance.

Figure 5. The mean instructional efficiency scores (a) and the mean performance efficiency scores (b) drawn in a Cartesian coordinate system. 
Figure 1

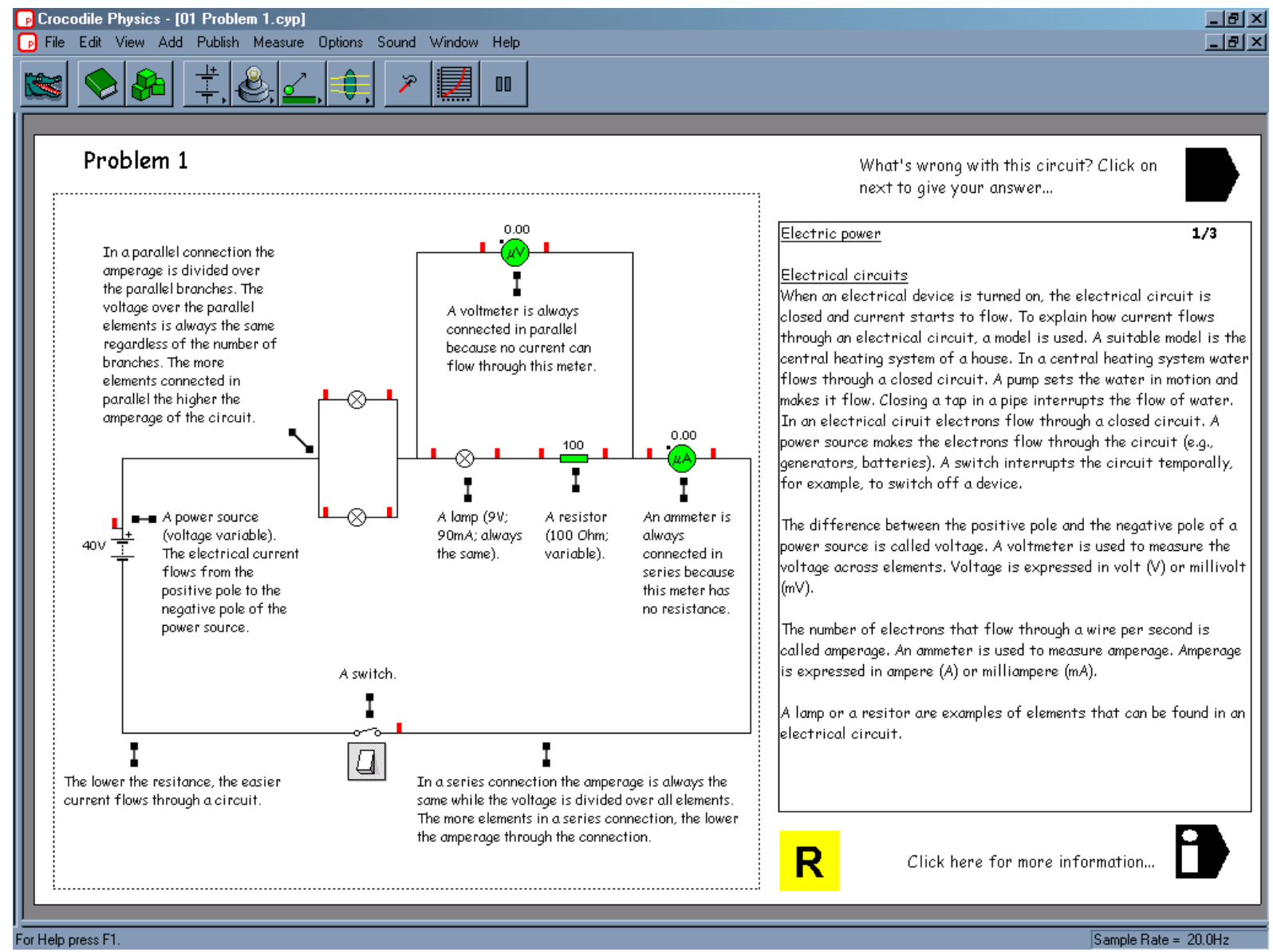


Figure 2

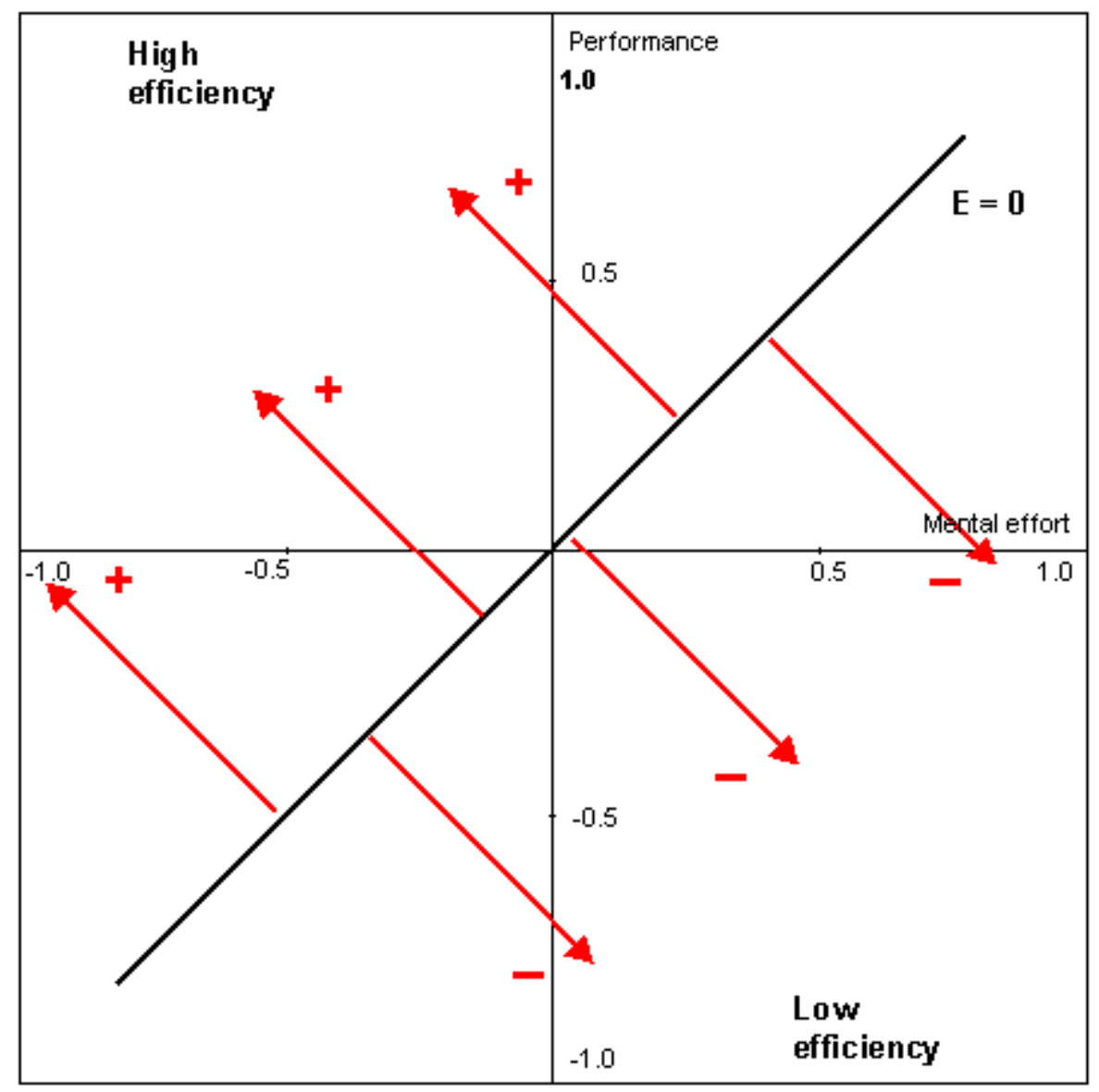


Figure 3

\section{Mental effort during practice}

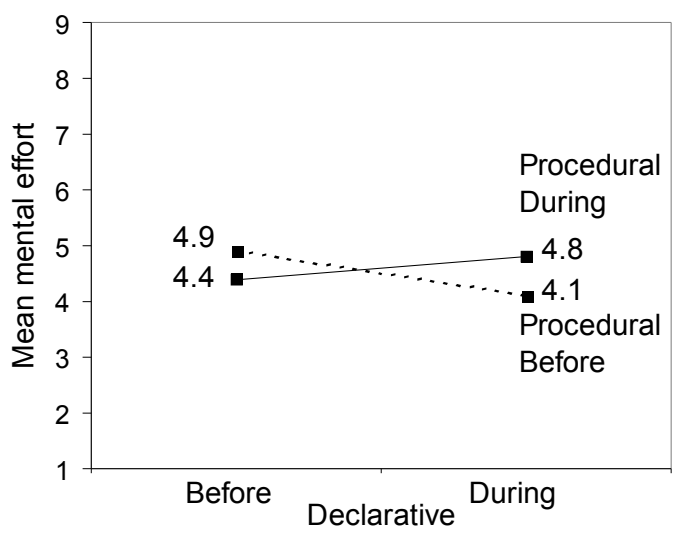


Figure 4

\section{Transfer test task performance}

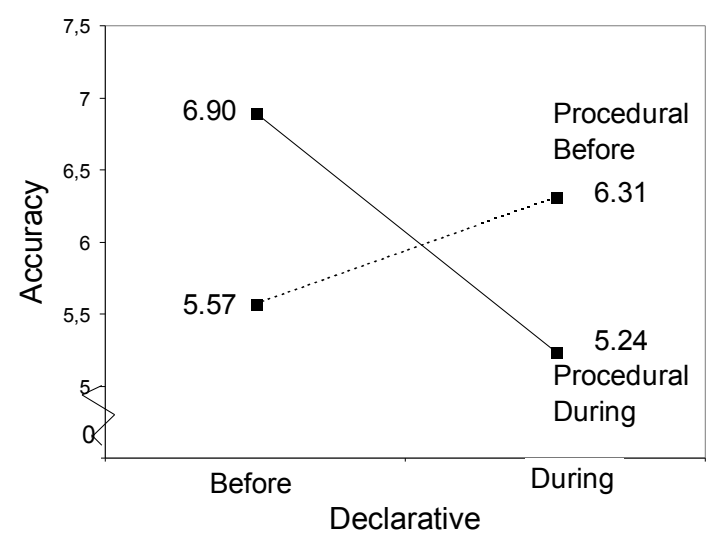


Figure 5

(a) Learning efficiency

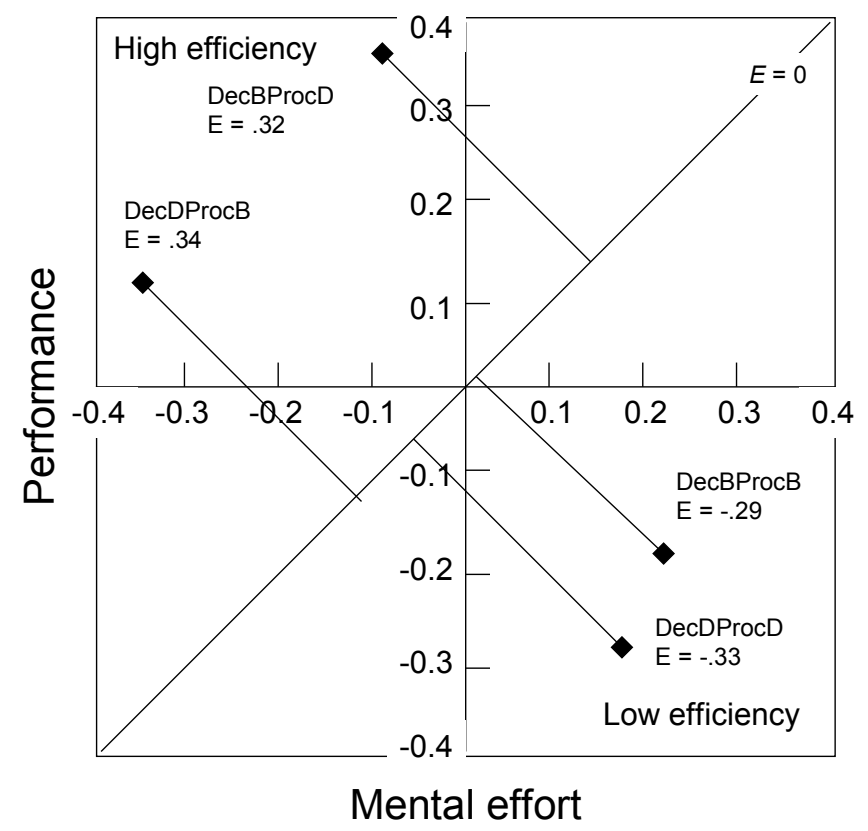

(b) Performance efficiency

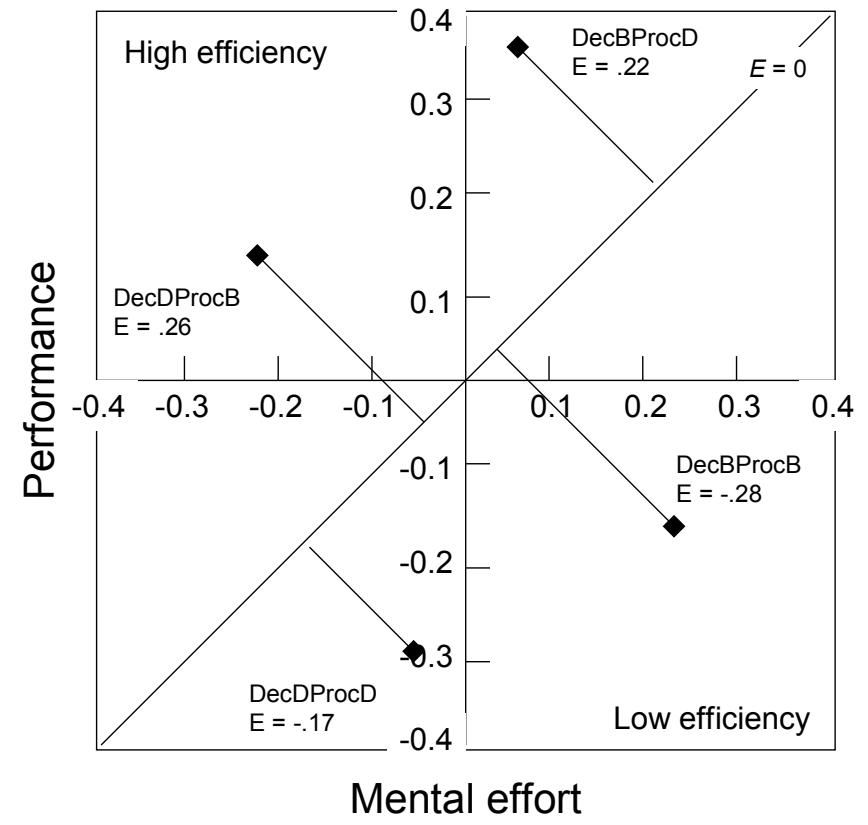

